\title{
A simple method for algal species discrimination in East China Sea, using multiple satellite imagery
}

\author{
Chi Feng $^{1 *}$, Joji Ishizaka ${ }^{2}$ and Shengqiang Wang ${ }^{3}$
}

\begin{abstract}
Satellites can help monitor harmful algal blooms in coastal regions. Methods have been developed using different satellite missions. However, it is necessary to develop a simple and useful method for discriminating harmful algal species that could be applied to multi-source satellite remote sensing reflectance spectra $\left(R_{\mathrm{rs}}(\lambda)\right)$. In this study, based on the bio-optical model, a backscattering indicator, $b_{\text {bp-index }}$ ( $\left.g r e e n\right)$, was found to be useful for species identification (Karenia mikimotoi and Prorocentrum donghaiense) combined with the red tide index (RI) in water blooms in the East China Sea (ECS). The MODIS, GOCI, and MERIS data collected between 2004 and 2020 were consistent for bloom discrimination, determining that $K$. mikimotoi exhibited lower $b_{\text {bp-index }}$ (green) values than $P$. donghaiense. The classification of the blooms is based on the following criteria: $R_{\mathrm{rs}}(555)<0.014 \mathrm{sr}^{-1}$ and $\mathrm{Rl}>2.8$ and (1) $b_{\text {bp-index }}$ (green) $>1.2$ $\times 10^{-3}$, classified as P. donghaiense blooms or (2) $b_{\text {bp-index }}$ (green) $<1.2 \times 10^{-3}$, classified as K. mikimotoi blooms. The inclusion of the $\mathrm{Rl}$ is necessary to directly detect the bloom area. Local bloom reports have confirmed the effectiveness of the bloom discrimination method. In addition, the advantages and limitations of the proposed method are discussed.
\end{abstract}

Keywords: Prorocentrum donghaiense, Karenia mikimotoi, Backscattering, Multiple sensor, East China Sea

\section{Introduction}

Harmful dinoflagellate blooms have been reported near the coast of the East China Sea (ECS) during summer since the 1990s (Zhou et al. 2003). Anthropogenic eutrophication is thought to be a significant factor in the frequent occurrence of harmful algal blooms (Gibert et al. 2005). According to the red tide reports from the Marine Environment Quality Bulletin of the State Ocean Administration (SOA) and Zhejiang Marine Monitoring and Forecasting Center, Prorocentrum donghaiense and Karenia mikimotoi are the common species of the dinoflagellate blooms. P. donghaiense is non-toxic, but affects

\footnotetext{
*Correspondence: fengchi9011@gmail.com

${ }^{1}$ School of Geography Science and Geomatics Engineering, Suzhou University of Science and Technology, 99 Xuefu Road, Suzhou 215009, China

Full list of author information is available at the end of the article
}

the marine ecosystem through large-scale biomass accumulation (Tang et al. 2006; Zhao et al. 2009). K. mikimotoi can secrete toxins and cause serious abalone mortality (Chen et al. 2021). In certain cases, $P$. donghaiense can co-bloom with $K$. mikimotoi blooms, causing serious mortality in marine fish (Zhou and Zhu 2006; Wang and 2009).

The differing optical properties of phytoplankton could help to build algorithms for harmful algal species discrimination using satellite data. Optical characteristics can arise from their absorption and backscattering properties. Previous studies have determined that $P$. donghaiense and K. mikimotoi contain unique pigments, including dinoxanthin and peridinin in $P$. donghaiense, and fucoxanthin, 19-hex-fucoxanthin, and 19-but-fucoxanthin in K. mikimotoi, with absorption in the range of 440-470 nm (Zapata et al. 2012; Clementsom and Wojtasiewicz 2019). The remote sensing reflectance $\left(R_{\mathrm{rs}}(\lambda)\right)$ 
from the water bloom was partly shaped by these accessory pigment absorption. However, because colored dissolved organic matter (CDOM) and non-algal components also produce strong absorption in short bands, the $R_{\mathrm{rs}}(\lambda)$ overlaps with algal and non-algal particle signals and could be ineffective in phytoplankton discrimination. Although there are other absorption peaks at approximately $570 \mathrm{~nm}$ and $640 \mathrm{~nm}$ due to the chlorophyll c3 in K. mikimotoi, it is difficult to discriminate the two phytoplankton species if the hyperspectral $R_{\mathrm{rs}}(\lambda)$ is not used (Shen et al., 2019).

Instead, methods based on backscattering properties has been developed for bloom discrimination. According to the bio-optical model, the spectral shape of $R_{\mathrm{rs}}(\lambda)$ is not only influenced by absorption but also by backscattering (Morel and Prieur 1977; Gordon et al. 1988). Different phytoplankton species exhibit varying magnitudes of backscattering or chlorophyll-specific backscattering spectrum, depending on their phytoplankton cell structure (Alvain et al. 2005). Sisiwanto et al. (2013) found that the remarkably lower reflectance of $\mathrm{K}$. miki$m o t o i$ in the green band indicates its lower $\mathrm{Chl}$ a-specific backscattering signature compared to that of the diatom blooms. Similar results were also found by Cannizzaro et al. $(2008,2019)$ when differentiating $K$. brevis from diatom blooms. These results indicate that lower backscattering might be a key signature for Karenia spp. when compared with diatoms. On the other hand, Shen et al. (2013) reported the experimentally measured backscattering spectra of Skeletonema costatum (diatom) and $P$. donghaiense, which revealed a higher backscattering in the case of $P$. donghaiense than the diatom.

To date, few studies have explored bloom discrimination between $P$. donghaiense and K. mikimotoi using satellite images. The purpose of this study was to characterize the optical properties of the two algal species and build a simple but effective method to separate the two algal species using multiple ocean color satellite data, without complicated data processing. Furthermore, we discuss the benefit and limitation of the proposed method for phytoplankton discrimination.

\section{Data and method}

\section{Local bloom data}

The study area covers most of the northwestern ECS $\left(27^{\circ}\right.$ $\mathrm{N}-32^{\circ} \mathrm{N}, 120^{\circ} \mathrm{E}-123^{\circ} \mathrm{E}$ ), including the Yangtze River Estuary and the coast of Zhejiang Province (Fig. 1). The bloom occurrence data were collected from the SOA and the Bulletin of China Marine Disaster by Zhejiang Ocean Forecast, which provides information regarding the occurrence time, location, area, and phytoplankton species of the bloom events, including the events caused

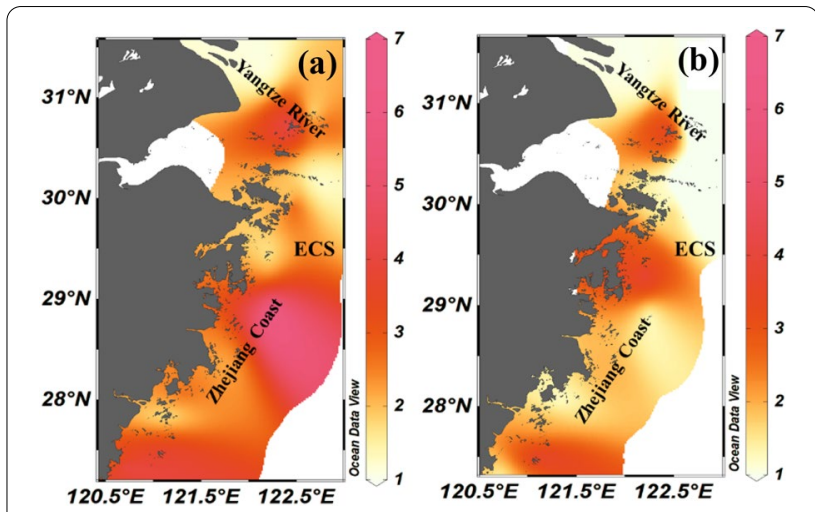

Fig. 1 Bloom frequency of $\mathbf{a}$ Prorocentrum donghaiense and $\mathbf{b}$ Karenia mikimotoi in East China Sea (ECS) during 2004-2020. Bloom occurrence data of $P$. donghaiense and K. mikimotoi were collected from the State Ocean Administration (SOA) and the Bulletin of China Marine Disaster from the Zhejiang Ocean Forecast

by P. donghaisense and K. mikimotoi. In this study, bloom reports from 2004 to 2020 were selected for the data analysis and method validation.

\section{GOCI, MODIS and MERIS data}

The Geostationary Ocean Color Imager (GOCI), ModerateResolution Imaging Spectroradiometer (MODIS), and Medium Resolution Imaging Spectrometer (MERIS) satellite data were selected for the study. The GOCI L1B (2010-2020) images were downloaded from the Korea Ocean Satellite Center (http://kosc.kordi.re.kr/) and then processed to L2 to obtain the $R_{\mathrm{rs}}(\lambda)$ using the GOCI data processing software (GDPs, version2.0), which uses the default atmospheric correction algorithm (Ryu et al. 2012). In addition, the MERIS Reduced Resolution (RR) L2 data (2004-2012) and MODIS L2 data (2004-2020) were downloaded from the NASA Ocean Color Web (https://oceancolor.gsfc.nasa.gov/) for the geographic regions of $27^{\circ} \mathrm{N}-32^{\circ} \mathrm{N}, 120^{\circ} \mathrm{E}-123^{\circ} \mathrm{E}$. The satellite images with minimal cloud cover were collected with the concurrent bloom observations. Pixels with negative values were excluded from the analysis. The central visual bands for GOCI, MERIS, and MODIS are $412 \mathrm{~nm}$, $443 \mathrm{~nm}, 490 \mathrm{~nm}, 555 \mathrm{~nm}, 660 \mathrm{~nm}, 680 \mathrm{~nm}, 745 \mathrm{~nm}$; $413 \mathrm{~nm}, 443 \mathrm{~nm}, 490 \mathrm{~nm}, 510 \mathrm{~nm}, 560 \mathrm{~nm}, 620 \mathrm{~nm}$, $665 \mathrm{~nm}, 681 \mathrm{~nm}$, and $709 \mathrm{~nm}$; and $412 \mathrm{~nm}, 443 \mathrm{~nm}$, $469 \mathrm{~nm}, 488 \mathrm{~nm}, 531 \mathrm{~nm}, 547 \mathrm{~nm}, 555 \mathrm{~nm}, 645 \mathrm{~nm}$, $667 \mathrm{~nm}, 678 \mathrm{~nm}$, respectively. The date of each satellite image concurrent with bloom occurrence are listed in Table 1.

For method development, six images were used for $K$. mikimotoi blooms, with two GOCI images, two MERIS images and two MODIS images; six images were used 
Table 1 Satellites images concurrent with the bloom occurrence time of GOCI, MODIS and MERIS

\begin{tabular}{|c|c|c|}
\hline Species & Satellite images & Observation date \\
\hline \multirow[t]{3}{*}{ Karenia mikimotoi } & $\mathrm{GOCl}$ & $\begin{array}{l}\text { June 5th, } 2012 \\
\text { June 30th, } 2017\end{array}$ \\
\hline & MERIS & $\begin{array}{l}\text { June 4th, } 2005 \\
\text { June 20th, } 2005\end{array}$ \\
\hline & MODIS & $\begin{array}{l}\text { Sept.8th, } 2014 \\
\text { Aug. 15th, } 2016\end{array}$ \\
\hline \multirow[t]{3}{*}{ Prorocentrum donghaiense } & $\mathrm{GOCl}$ & $\begin{array}{l}\text { May 12th, } 2016 \\
\text { May 23th, } 2014\end{array}$ \\
\hline & MERIS & $\begin{array}{l}\text { May 16th, } 2010 \\
\text { July 9th, } 2010\end{array}$ \\
\hline & MODIS & $\begin{array}{l}\text { May 24th, } 2019 \\
\text { Apr. 24th, } 2020\end{array}$ \\
\hline
\end{tabular}

The images in the table were selected for method development

for $P$. donghaiense blooms, with two GOCI images, two MERIS images and two MODIS images. The observation time for MERIS and MODIS images were around 01:00(GMT) and 05:00 (GMT), respectively. The GOCI provides eight images per day from 00:00 (GMT) to 07:00 (GMT). Since the phytoplankton would grow rapidly under suitable light intensity, and thus make significant contribution to the variation of inherent optical properties. The GOCI images at 04:00 (GMT) around noontime was chosen for method development to discriminate phytoplankton species, which could also help us to compare the optical variation with other two satellite data during daytime on bloom days. To validate the developed method, two MODIS images and two GOCI images (at noontime) were tested for $K$. mikimotoi blooms and $P$. donghaiense blooms detection, respectively.

\section{Red tide index (RI)}

Bloom pixels should be first detected before the differentiation of phytoplankton species. Indices have been developed for red tide detection in East China Sea, such as Bloom Index (BI) developed by Shang et al. (2014), Red tide Index (RI) developed by Lou et al. (2014) and Algal bloom Ration $\left(R_{\mathrm{AB}}\right)$ developed by Tao et al. (2015). Considering the band setting of the satellite sensors mentioned in section "GOCI, MODIS and MERIS data", the $\mathrm{RI}$ is most suitable for bloom detection in this study. The red tide index (RI) was determined using three bands from the satellite $R_{\mathrm{rs}}(\lambda)$ :

$$
\mathrm{RI}=\frac{R_{\mathrm{rs}}(555)-R_{\mathrm{rs}}(443)}{R_{\mathrm{rs}}(490)-R_{\mathrm{rs}}(443)}
$$

The design of the RI could suppress the effect of resuspended sediments by subtracting the $R_{\mathrm{rs}}(443)$ in the green to blue band ratio. The index performed well for bloom detection in the ECS. A threshold of 2.8 was chosen for the application of RI reported by Lou et al. (2014). A higher value implies a higher density of the bloom. In the bloom detection procedure for MODIS data, the $R_{\mathrm{rs}}(\lambda)$ at $488 \mathrm{~nm}$ was used instead of $490 \mathrm{~nm}$.

In addition, considering that harmful dinoflagellate blooms in the ECS were often observed near inshore regions, it is crucial to separate turbid water from blooms at the beginning of the method to eliminate the influence of non-algal suspended sediments on backscattering. Previous studies showed that the $R_{\mathrm{rs}}(\lambda)$ of turbid water from ECS presented high $R_{\mathrm{rs}}(\lambda)$ from green to near red bands and the satellite $R_{\mathrm{rs}}(555)$ has been proved to be a good indicator of water turbidity (Yamaguchi et al. 2012). Pixels with threshold of $R_{\mathrm{rs}}(555)>0.014 \mathrm{sr}^{-1}$ was flagged turbid water in Tao et al. (2015). In this study, an additional threshold of $R_{\mathrm{rs}}(555)<0.014 \mathrm{sr}^{-1}$ was used to exclude the influence of turbid water. Finally, the bloom water was detected by $R_{\mathrm{rs}}(555)<0.014 \mathrm{sr}^{-1}$ and RI $>2.8$.

\section{Index based on bio-optical model}

A two-band blended reflectance index, $b_{\mathrm{bp}_{-i n d e x}}$, based on a bio-optical model, was developed by Feng et al. (2020) using MODIS data to help indicate the backscattering characteristics of the phytoplankton. The index was built on the bio-optical theory that $R_{\mathrm{rs}}(\lambda)$ is the function of the absorption $\mathrm{a}(\lambda)$ and backscattering $b_{b}(\lambda)$ (Gordon et al. 1988). Assumptions for absorption a $(\lambda)$ and backscattering $b_{b}(\lambda)$ were made in the green and red bands to derive the $b_{\mathrm{bp}_{- \text {index }}}$ (details are available in Feng et al. 2020, absorption coefficient of the algae species refers to Shen et al. 2019). The index was calculated as follows:

$$
b_{\mathrm{bp}-\text { index }}\left(\lambda_{1}\right)=\frac{R_{\mathrm{rs}}\left(\lambda_{1}\right) R_{\mathrm{rs}}\left(\lambda_{2}\right)}{R_{\mathrm{rs}}\left(\lambda_{1}\right)-R_{\mathrm{rs}}\left(\lambda_{2}\right)} * \kappa
$$

where $\lambda_{1}$ represents the wavelength in the green band, and $\lambda_{2}$ represents the wavelength in the red band. $\kappa$ refers to the absorption coefficient difference between $\lambda_{1}$ and $\lambda_{2}$ in pure water. Dierssen et al. (2006) has demonstrated that there is backscattering difference between phytoplankton. For the species in ECS, Shen et al. (2013) has revealed the differed inherent optical properties in harmful algal species. However, there is no direct evidence of the backscattering properties in K. mikimotoi bloom waters, comparing with $P$. donghaiense blooms. As mentioned above, the backscattering characteristics could be described by $b_{\mathrm{bp}-\text { index }}$ based on bio-optical models. The index was found to be useful in representing backscattering difference between phytoplankton (Feng et al. 2021), which could help to compare the backscattering 
properties between $K$. mikimotoi and $P$. donghaiense bloom waters through satellite data.

For the GOCI data, $\lambda_{1}=550 \mathrm{~nm}, \lambda_{2}=660 \mathrm{~nm}$, and $\kappa$ $=0.35$. For the MERIS data, $\lambda_{1}=560 \mathrm{~nm}, \lambda_{2}=665 \mathrm{~nm}$, and $\kappa=0.37$. For the MODIS data, $\lambda_{1}=555 \mathrm{~nm}$, $\lambda_{2}=645 \mathrm{~nm}$, and $\kappa=0.37$. In the following parts, $b_{\mathrm{bp}-\text { index }}($ green $)$ was used instead of $b_{\mathrm{bp}-\text { index }}\left(\lambda_{1}\right)$ to
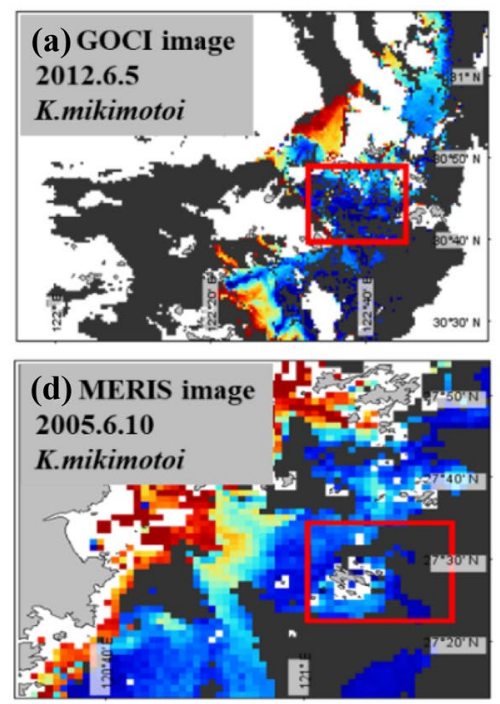

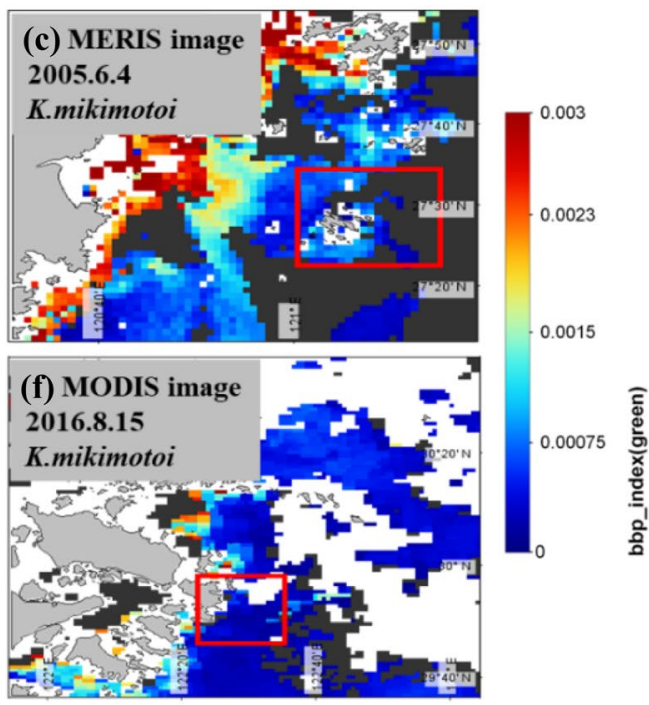

g 2004-2020. a, b b bp_index (green) map derived by GOCl
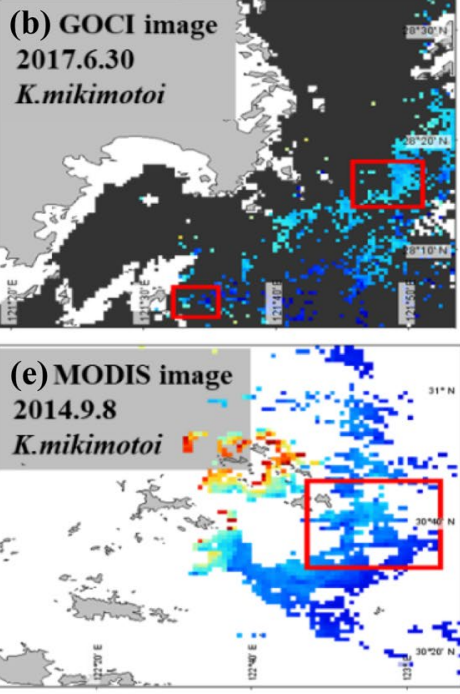
images. $\mathbf{c}, \mathbf{d} b_{\text {bp_index }}$ (green) map derived by MERIS images. $\mathbf{e}, \mathbf{f} b_{\text {bp_index }}$ (green) map derived by MODIS images. The highlighted regions (red rectangles) indicate occurrences of K. mikimotoi blooms that were recorded by State Ocean Administration (SOA) and the Bulletin of China Marine

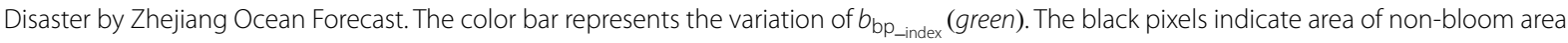
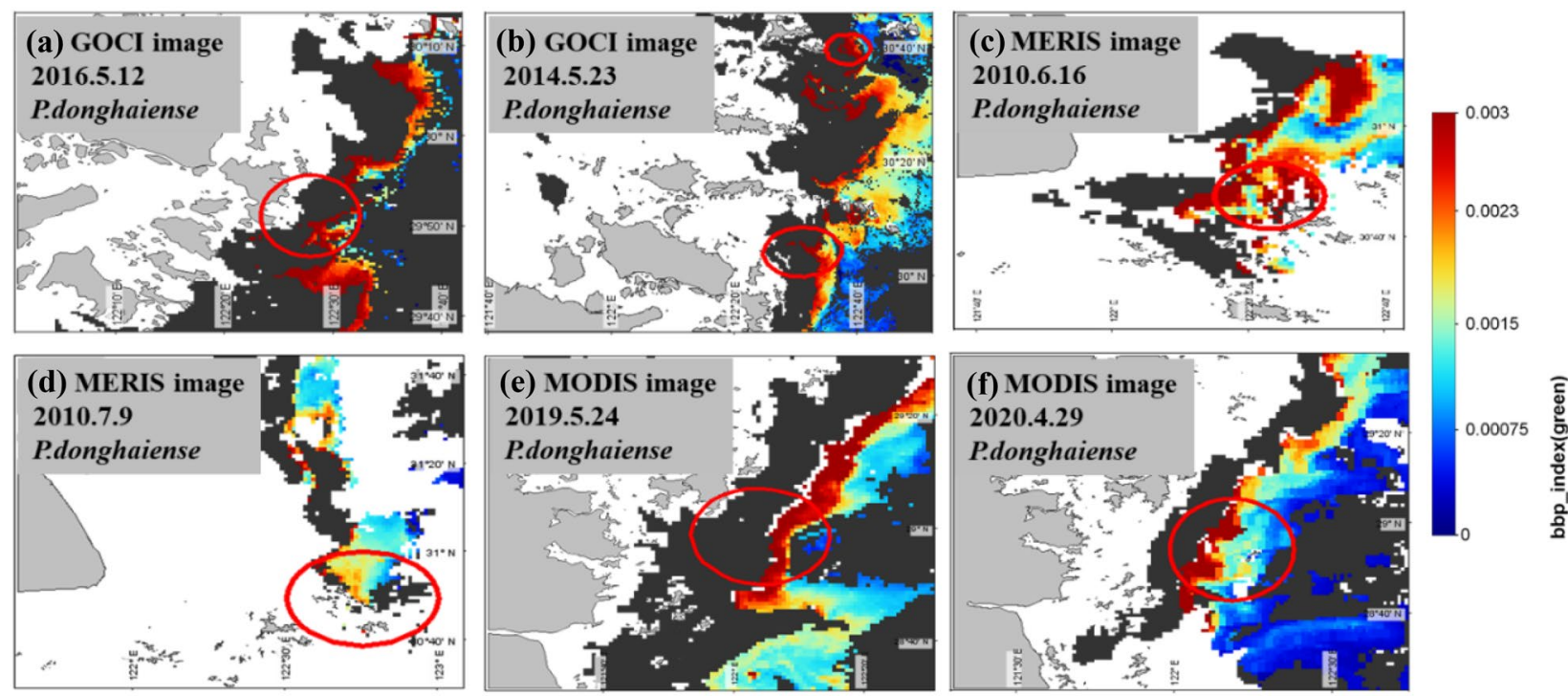

Fig. 3 Satellite imagery derived $b_{b p_{\text {_index }}}$ (green) of Prorocentrum donghaiense blooms water from 2004 to 2020 . a, b $b_{\mathrm{bp}}$ index $(g r e e n$ ) map derived by $\mathrm{GOCl}$ images. $\mathbf{c}, \mathbf{d} b_{\mathrm{bp}_{\text {_index }}}$ (green) map derived by MERIS images. e, $\mathbf{f} b_{\mathrm{bp} \text { _index }}$ (green) map derived by MODIS images. The highlighted regions (red circles) indicate occurrences of Prorocentrum donghaiense blooms that were recorded by the SOA and the Bulletin of China Marine Disaster from the Zhejiang Ocean Forecast. The color bar represents the variation of $b_{\text {bp_index }}$ (green). The black pixels indicate area of non-bloom area 
refer the backscattering properties around green bands of bloom waters.

\section{Results}

Backscattering properties of water blooms derived using multiple satellite imagery

Figures 2 and 3 present the derived $b_{\mathrm{bp}-\text { index }}$ (green) from the GOCI, MERIS, and MODIS data captured during the bloom periods of 2004-2020. The bloom regions with $\mathrm{RI}>2.8$ are colored according to the $b_{\text {bp-index }}$ (green) variation. The areas highlighted with red rectangles and circles coincide with the observed local bloom reports. The $b_{\mathrm{bp}-\text { index }}$ (green) estimated using Eq. (2) demonstrates that when the value is lower, an algal bloom with $K$. mikimotoi is more likely to occur. Otherwise, the probability of $P$. donghaiense bloom occurrence is higher. The occurrence of $K$. mikimotoi and $P$. donghaisense were also concurrently verified by China Ocean Bulletins and the results published in Tao et al. (2015) and Shang et al. (2014). The statistics of the $b_{\mathrm{bp}-\text { index }}$ (green) from the two algal species are listed in Table 2. Even though there were band adjustments for the $b_{\mathrm{bp}-\text { index }}($ green) derivation when using multiple satellite data, $P$. donghaisense exhibited a $b_{\mathrm{bp}-\text { index }}($ green $)$ that was almost ten times higher than that of the K. mikimotoi blooms, regardless of the difference in overpassing time between sensors. Specifically, the $b_{\mathrm{bp}-\text { index }}($ green $)$ values of the K. mikimotoi blooms were within $6 \times 10^{-4} \pm 3 \times 10^{-4}$, while that of the $P$. donghaiense blooms was $2.5 \times 10^{-3} \pm 2.5 \times 10^{-3}$.

In addition, the $b_{b p_{\text {index }}}$ (green) by hourly GOCI images (eight images per day) from K. mikimotoi bloom patches on June 30, 2017 and P. donghaiense bloom patches on May 12, 2016 were derived (see Fig. 4). Among the duration of bloom, the mean $b_{\mathrm{bp}_{\text {index }}}$ (green) is weakly varied during the daytime from 8:00 to 15:00. Specifically, the mean $b_{\mathrm{bp}}$ index $($ green) values of $K$. mikimotoi varied around 0.0008 , with maximum up to

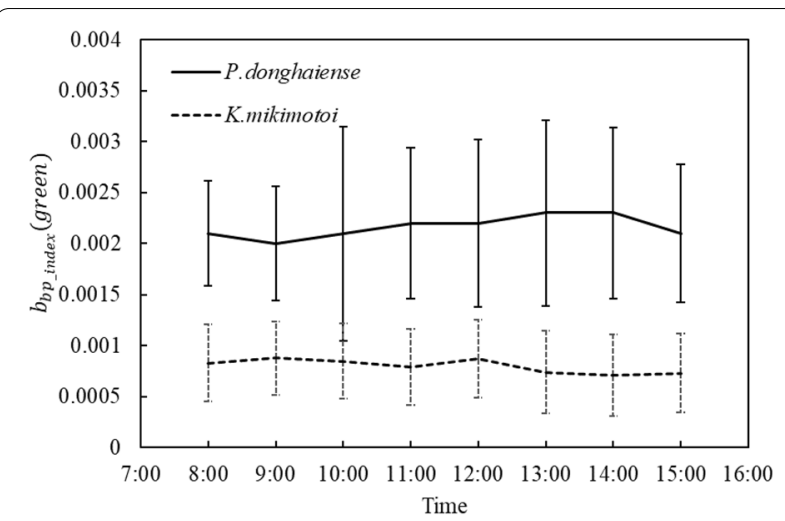

Fig. 4 Hourly variation of $b_{\mathrm{bp}-\text { index ( }}$ reen) on the bloom days of $P$. donghaiense on May 12, 2016 and K. mikimotoi on June 30, 2017. The black represents the $b_{\mathrm{bp} \text {-index }}$ (green) from $P$. donghaiense blooms, the black dotted line represents $b_{\mathrm{bp}-\text { index }}$ (green) from the K. mikimotoi blooms

0.0009 . For $b_{\mathrm{bp}_{\text {index }}}$ (green) of P. donghaiense bloom, the averaged value was between 0.002 and 0.0023 , with average 0.0021 . The hourly variations demonstrate that the backscattering properties of bloom waters was stable despite the environment variations, which help us to apply the bloom discrimination method using multiple sensors without considering the sensing time.

\section{Discrimination of algal bloom using satellite data}

Combining the $b_{\mathrm{bp}-\text { index }}$ (green) results and local bloom reports, a criterion is proposed using linear Support Vector Machines (SVM) method, for differentiating K. mikimotoi and $P$. donghaiense blooms using satellite imagery:

when $R_{\mathrm{rs}}(555)<0.014 \mathrm{sr}^{-1}$ and $\mathrm{RI}>2.8$, if $b_{\text {bp-index }}($ green $)<1.2 \times 10^{-3}$, it suggests a K. mikimotoi bloom, and if $b_{\mathrm{bp}-\text { index }}($ green $)>1.2 \times 10^{-3}$, it suggests a $P$. donghaiense bloom.

The proposed method was validated using independent MODIS and GOCI images when the bloom events

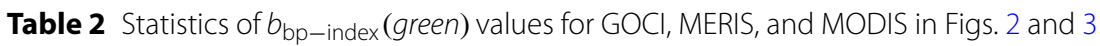

\begin{tabular}{|c|c|c|c|c|c|c|}
\hline \multirow[t]{2}{*}{ Satellite images } & \multicolumn{3}{|c|}{ Karenia mikimotoi } & \multicolumn{3}{|c|}{ Prorocentrum donghaiense } \\
\hline & $N$ & Mean & Standard deviation & $N$ & Mean & $\begin{array}{l}\text { Standard } \\
\text { deviation }\end{array}$ \\
\hline \multirow[t]{2}{*}{$\mathrm{GOCl}$} & 420 & 0.0007 & 0.0003 & 420 & 0.0025 & 0.0011 \\
\hline & 116 & 0.0008 & 0.0003 & 96 & 0.0023 & 0.0009 \\
\hline \multirow[t]{2}{*}{ MODIS } & 179 & 0.0004 & 0.0004 & 30 & 0.0031 & 0.0004 \\
\hline & 36 & 0.0007 & 0.0002 & 275 & 0.0027 & 0.001 \\
\hline \multirow[t]{2}{*}{ MERIS } & 139 & 0.0006 & 0.0001 & 125 & 0.0017 & 0.0004 \\
\hline & 137 & 0.0006 & 0.0002 & 91 & 0.0024 & 0.0006 \\
\hline Average & & 0.0006 & 0.0003 & & 0.0025 & 0.001 \\
\hline
\end{tabular}

$N$ in the table refer to the pixle numbers in each bloom region 

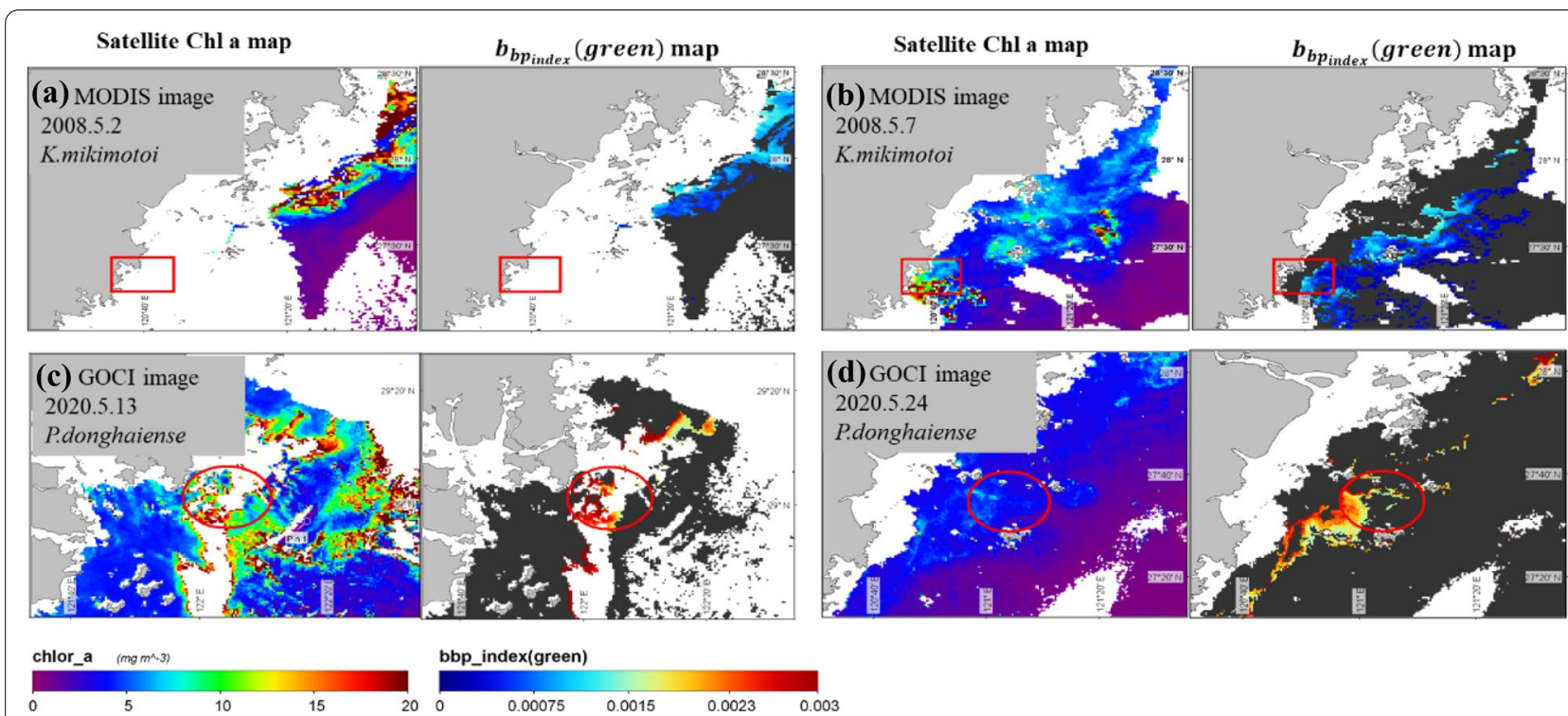

Fig. 5 Satellite imagery derived Chl a maps and $b_{\text {bp_index }}$ (green) maps (a, b) K. mikimotoi blooms from MODIS images and (c, d) P. donghaiense blooms from GOCl images, respectively. The highlighted regions (red rectangles and circles) indicate occurrences of K. mikimotoi and $P$. donghaiense bloom regions that were recorded by the State Ocean Administration (SOA) and the Bulletin of China Marine Disaster from the Zhejiang Ocean Forecast. The color bar represents the variation of satellite derived $\mathrm{Chl}$ a and $b_{\mathrm{bp} \text {-index }}$ (green), respectively. The black pixels indicate area of non-bloom area

were included in local reports (Fig. 5). In May 2008, high satellite-derived $\mathrm{Chl}$ a area was found near the coast of Zhejiang. In those patches, pixels with $b_{\mathrm{bp}-\text { index }}$ (green) values $<1.2 \times 10^{-3}$ were found, indicating the occurrence of K. mikimotoi blooms. In May 2020, the high satellitederived $\mathrm{Chl}$ a map indicated blooming patches near the Zhejiang coast, while the $b_{\mathrm{bp}-\text { index }}($ green $)>1.2 \times 10^{-3}$ suggested a bloom of $P$. donghaiense. Although there were no satellite data in the bloom region, as demonstrated in Fig. 4a, the bloom reports in early May 2008 recorded near the Zhejiang coast can help to confirm the occurrence of $K$. mikimotoi blooms. In general, these results were consistent with the local observations reported by the SOA and the Bulletin of China Marine Disaster from the Zhejiang Ocean Forecast.

\section{Discussion}

Although there has been no in situ measurement for backscattering properties, previous studies have provided some reasons for the $b_{\mathrm{bp}-\text { index }}$ (green) variations. For example, Cannizzaro et al. (2008) found that the $K$. brevis demonstrated a lower backscattering signal when blooms occurred with biomass $>10^{5}$ cells $/ \mathrm{ml}$. Ahmed et al. (2016) and Siswanto et al. 2013) also showed the lower $R_{r s}(555)$ signal in the K. brevis- and K. mikimotoidominated bloom waters. Amin et al. (2009) determined that the $K$. brevis exhibited a stronger fluorescence signal at approximately $667 \mathrm{~nm}$ when biomass $>10^{4}$ cells/ $\mathrm{ml}$ when compared with non-K. brevis blooms. Kurekin et al. (2013) found that the radiance at $667 \mathrm{~nm}$ was larger for $K$. mikimotoi blooms. The normalized $R_{\mathrm{rs}}(\lambda)$ of water blooms modeled by Shen et al. (2019) demonstrated a significant fluorescence signal at approximately $670 \mathrm{~nm}$ for $K$. mikimotoi blooms. In this study, we also found that the satellite $R_{\mathrm{rs}}(\lambda)$ of the K. mikimoto $i$ bloom regions presented lower values than that of $P$. donghaiense bloom, with apparent fluorescence emission in the red bands (Fig. 6). Thus, with the lower radiance signal at green band and high fluorescence signal at red band, $K$. mikimotoi exhibited a lower $b_{\mathrm{bp}-\text { index }}$ (green) value than that of $P$. donghaiense.

From a bio-optical perspective, the effective $b_{\text {bp-index }}$ (green) method could be related with the difference in backscattering properties, which result from the cell size, cell shape, and cell structure between $K$. mikimotoi and P. donghaiense (Vaillancourt et al. 2004). Although the cell size of $K$. mikimotoi $((16-30) \times(20-30)$ $\mu \mathrm{m}$ in width $\times$ length) is larger than that of $P$. donghaiense $((10-13) \times(19-22) \mu \mathrm{m}$ in width $\times$ length) $($ Lü et al., 2019; Lu et al. 2001), there is no cell walls in K. mikimotoi cells, which might weaken the scattering coefficient of the accumulated phytoplankton. In addition to the difference in cell features, the environmental conditions during bloom formation might also be responsible for the backscattering difference. Dang et al. (2015) found a scarcity of submicron particles in the K. mikimotoi water blooms 

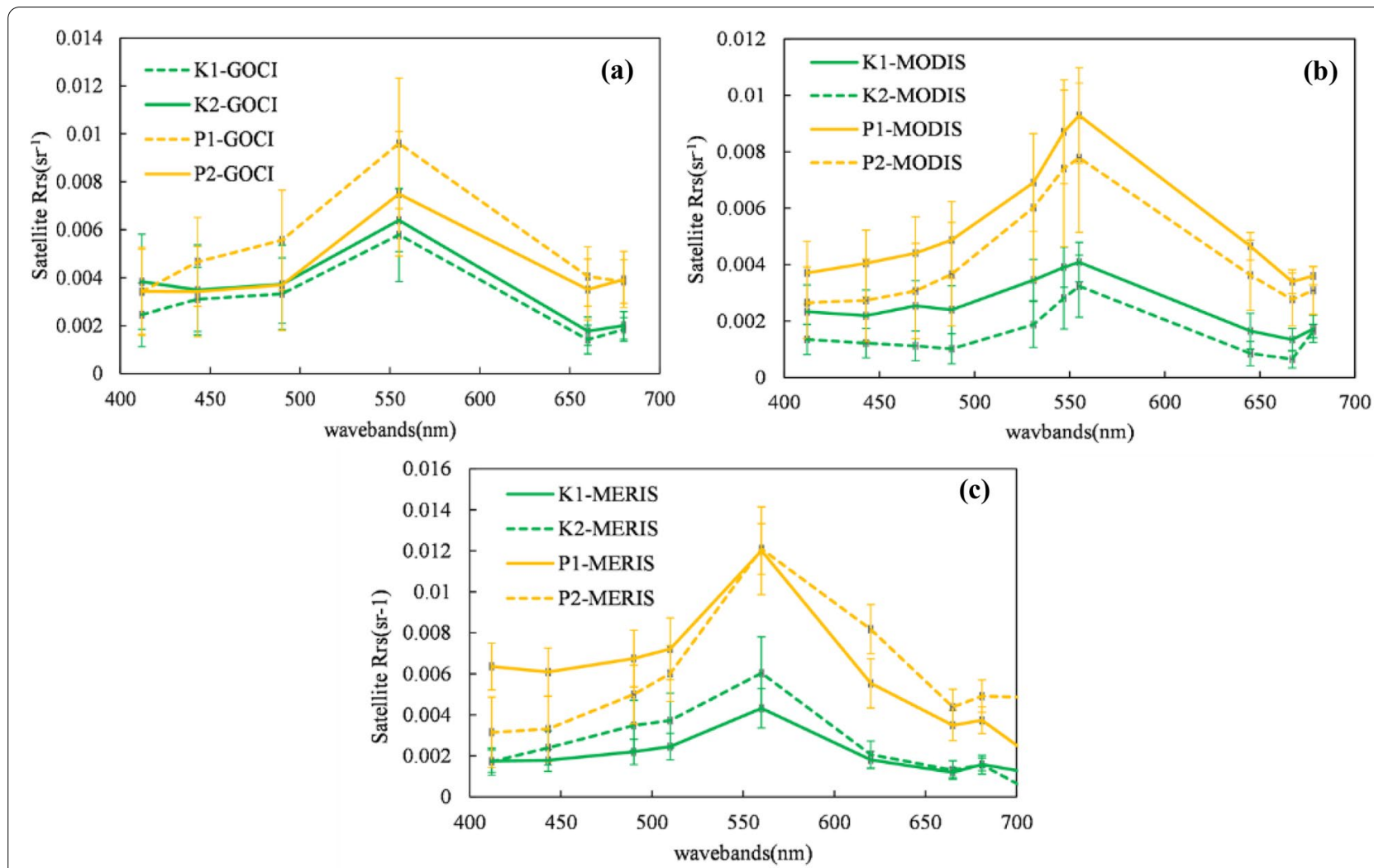

Fig. 6 Satellite $R_{r 5}(\lambda)$ extracted from the bloom regions by a GOCI, b MODIS, and c MERIS images in Figs. 2 and 3. The K1-GOCI, K2-GOCI, K1-MODIS, K2-MODIS, K1-MERIS and K2-MERIS represent the averaged satellite $R_{\mathrm{rs}}(\lambda)$ of $K$. mikimotoi bloom regions from GOCI, MODIS and MERIS images in Fig. 2. The P1-GOCI, P2-GOCI, P1-MODIS, P2-MODIS, P1-MERIS and P2-MERIS represent the averaged satellite $R_{\mathrm{rS}}(\lambda)$ of $P$. donghaiense bloom regions from GOCl, MODIS and MERIS images in Fig. 3

due to the reduced grazing pressure caused by cellular toxicity. In addition, $P$. donghaiense was found to possess a relatively wide salinity tolerance, while $K$. mikimotoi is sensitive to high salinity due to the lack of a cell wall (Zhou et al. 2003; Aoki et al. 2017). In most cases, the $K$. mikimotoi blooms aggregate in low-turbidity and lowsalinity conditions (Robin et al. 2013; Barnes et al. 2015; Aoki et al. 2017), while $P$. donghaiense blooms could survive in more turbid water because of its high competition coefficient under low light intensity (Xu et al. 2010). Thus, the non-algal particles in the P. donghaiense blooms could also be attributed to its higher backscatter signal in bloom conditions.

Moreover, since the $b_{\mathrm{bp}-\text { index }}$ (green) was calculated using the satellite $R_{\mathrm{rs}}(\lambda)$ directly, while the $R_{\mathrm{rs}}(\lambda)$ is functional to the reciprocal between $b_{b p}$ and $a(\lambda)$ (Gordon et al. 1988). Therefore, the differences of $b_{\text {bp-index }}$ (green) value are also likely related to the absorption $a(\lambda)$ variations of $K$. mikimotoi and $P$. donghaiense. According to the absorption spectrum measured by Shen et al. (2019), K. mikimotoi exhibits much higher values in the visible bands than $P$. donghaiense.
Such differences could arise from the different cellular pigment contents of each species (Zapata, et al., 2012; Huang et al., 2021). The main accessory pigments are peridinin in $P$. donghaiense (peridinin/chl a $\sim 0.824$ ), and fucoxanthin (fucoxanthin/chl a $0.33-1.75$ ) in $K$. mikimotoi. Other pigments such as dinoxanthin (in $P$. donghaisense) and Chl c3 (K. mikimotoi) also contribute to the absorption coefficient. Therefore, it is likely that the lower $R_{\mathrm{rs}}(\lambda)$ of $K$. mikimotoi bloom water is partly due to its higher proportion of accessory pigments. The difference in pigments absorption contained in $K$. mikimoto $i$ and $P$. donghaiense thus leading to a distinctive $b_{\mathrm{bp} \text {-index }}($ green) values for the two algal species. Note that non-algal particles could also make contribution to the backscattering variation. In this study, the extremely turbid water was excluded in the first steps of bloom detection by threshold $R_{\mathrm{rs}}(555)<0.014 \mathrm{sr}^{-1}$, more work was done by subtracting the $R_{\mathrm{rs}}(443)$ in the calculation of RI to minimize the influence of non-algal particles. Besides, we assumed that the inherent optical properties of bloom waters were result from phytoplankton particles in the retrieval of $b_{\mathrm{bp}-\text { index }}$ (green). 
Therefore, the backscattering contributed by minor non-algal particles were omitted in this study. On the other hand, it was found that most of the pixels with $R_{\mathrm{rs}}(555)>0.014 \mathrm{sr}^{-1}$ showed $b_{\mathrm{bp}-\text { index }}$ (green) value around $10^{-2}$, while the results of bloom waters showed the $b_{\mathrm{bp}-\text { index }}$ (green) value around $10^{-3}$. Regardless of the absorption assumption in $b_{\mathrm{bp}-\text { index }}($ green) retrieval, the index might also be used to separate turbid water from bloom waters.

This method might be applied in other regions for bloom discrimination. However, band adjustment is needed when considering the absorption assumption in the visible bands. Blue bands are not recommended for the index retrieval, because there could be shape variation with the increasing $\mathrm{Chl}$ a in nanophytoplankton (Jiang 2014). The shape in longer wavelength is more stable and could help to discriminate the target the algae species. More work is still need to be done when there are two or three species mixed in the bloom regions, other supplementary is necessary for phytoplankton differentiation.

\section{Conclusions}

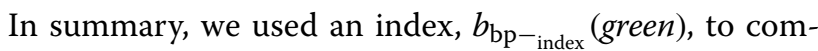
pare the backscattering properties of $K$. mikimotoi and $P$. donghaiense using multiple satellite images. By the $b_{\text {bp- }}{ }_{\text {index }}$ (green), a significant difference in backscattering was found between the K. mikimotoi and $P$. donghaiense water blooms. This method was found to be useful in bloom discrimination using the GOCI, MODIS, and MERIS data. This proof-of-concept study demonstrates that there is likely a backscattering difference between the two species. Such optical characteristics of backscattering could arise not only from the cellular structures of the species but also from the environmental conditions during phytoplankton accumulation. This method could be applied to other regions for algal species discrimination when the $R_{\mathrm{rs}}(\lambda)$ signal or $a(\lambda)$ signal is not easily distinguishable using the current published methods. Further investigations into the inherent optical characteristics of other algal species in complicated coastal regions is necessary, and the index $b_{\mathrm{bp}-{ }_{\text {index }}}$ (green) should be calibrated with in situ data to reduce the influence of non-algal suspended particles in turbid waters.

\section{Acknowledgements}

We wish to thank NASA and Korea Ocean Satellite Center for providing Moderate-resolution Imaging Spectroradiometer (MODIS) Aqua L2 data, Medium Resolution Imaging Spectrometer (MERIS) reduced resolution L2 data and Geostationary Ocean Color Imager (GOCI) L1B data. We wish to thank Zhejiang Ocean Forecast (https://zjocean.org.cn/ecowarn/tidewarn) and Bulletin of China Marine Disaster for providing the information of harmful blooms in ECS.

\section{Authors' contributions}

CF, Jl conceived of this study. CF developed the methods. CF collected, analyzed data and processed satellite images. CF write the manuscript. JI and WQ provided supervision. All authors contributed to editing this manuscript. All authors read and approved the final manuscript.

\section{Funding}

This work was supported by the Suzhou University of Science and Technology with Grant Numbers 332114802

\section{Data availability}

The bloom information and processed satellite images could be found at https://doi.org/10.5281/zenodo.5595494; The method for $\boldsymbol{b}_{\mathrm{bp}-\text { inder }}$ retrieval could be found at:https://agupubs.onlinelibrary.wiley.com/doi/full/10.1029/ 2020JC016924 (for GOCl image) and https://www.mdpi.com/2072-4292/12/9/ 1504 (for MODIS image).

\section{Declarations}

\section{Competing interests}

The authors declare that the research was conducted in the absence of any commercial or financial relationships that could be construed as a potential conflict of interest.

\section{Author details}

${ }^{1}$ School of Geography Science and Geomatics Engineering, Suzhou University of Science and Technology, 99 Xuefu Road, Suzhou 215009, China. ${ }^{2}$ Institute for Space-Earth Environmental Research (ISEE), Nagoya University, Furo-cho, Chikusa-ku, Nagoya 464-8601, Aichi, Japan. ${ }^{3}$ School of Marine Sciences, Nanjing University of Information Science \& Technology, 219 Ningliu Road, Nanjing 210044, China.

Received: 9 December 2021 Accepted: 8 February 2022

Published online: 27 February 2022

\section{References}

Alvain S, Moulin C, Dandonneau Y, Bréon FM (2005) Remote sensing of phytoplankton groups in case 1 waters from global SeaWiFS imagery. Deep Sea Res Part I 52:1989-2004. https://doi.org/10.1016/j.dsr.2005.06.015

Ahmed S, El-Habashi A (2016) Neural network retrievals of Karenia brevis harmful algal blooms in the West Florida Shelf (Conference Presentation). https://www.spiedigitallibrary.org/conference-proceedings-of-spie/ 9999/99990H/Neural-network-retrievals-of-Karenia-brevis-harmful-algalblooms-in/10.1117/1.2242079.short.

Amin R, Gilerson A, Zhou J, et al (2009) Impacts of atmospheric corrections on algal bloom detection techniques. In: Eighth Conference on Coastal Atmospheric, Oceanic Prediction, Processes, USA. academia.edu

Aoki K, Kameda T, Yamatogi T et al (2017) Spatio-temporal variations in bloom of the red-tide dinoflagellate Karenia mikimotoi in Imari Bay, Japan, in 2014: factors controlling horizontal and vertical distribution. Mar Pollut Bull 124:130-138. https://doi.org/10.1016/.j.marpolbul.2017.07.019

Barnes MK, Tilstone GH, Smyth TJ et al (2015) Drivers and effects of Karenia mikimotoi blooms in the western English Channel. Prog Oceanogr 137:456-469. https://doi.org/10.1016/j.pocean.2015.04.018

Cannizzaro JP, Carder KL, Chen FR et al (2008) A novel technique for detection of the toxic dinoflagellate, Karenia brevis, in the Gulf of Mexico from remotely sensed ocean color data. Cont Shelf Res 28:137-158. https://doi org/10.1016/j.csr.2004.04.007

Cannizzaro JP, Barnes BB, Hu C et al (2019) Remote detection of cyanobacteria blooms in an optically shallow subtropical lagoonal estuary using MODIS data. Remote Sens Environ 231:111227. https://doi.org/10.1016/j.rse.2019. 111227

Chen HB, Wang K, GuoLiu HGH (2021) Karenia mikimotoi blooms in coastal waters of China from 1998 to 2017. Estuar Coast Shelf Sci 249:107034. https://doi.org/10.1016/j.ecss.2020.107034 
Clementson LA, Wojtasiewicz B (2019) Dataset on the absorption characteris tics of extracted phytoplankton pigments. Data Brief 24:103875. https:// doi.org/10.1016/j.dib.2019.103875

Dang L-X, Li Y, Liu F et al (2015) Chemical response of the toxic dinoflagellate Karenia mikimotoi against grazing by three species of zooplankton. J Eukaryot Microbiol 62:470-480. https://doi.org/10.1111/jeu.12201

Dierssen HM, Kudela RM, Ryan JP et al (2006) Red and black tides: Quantitative analysis of water-leaving radiance and perceived color for phytoplankton, colored dissolved organic matter, and suspended sediments. Limnol Oceanogr 51(6):2646-2659. https://doi.org/10.4319/lo.2006.51.6.2646

Feng C, Ishizaka J, Saitoh K et al (2020) A Novel method based on backscattering for discriminating summer blooms of the Raphidophyte (Chattonella spp.) and the Diatom (Skeletonema spp.) using MODIS images in Ariake Sea, Japan. Remote Sens 12:1504

Feng C, Ishizaka J, Saitoh K et al (2021) Detection and tracking of Chattonella spp. and Skeletonema spp. blooms using geostationary ocean color imager (GOCl) in Ariake Sea, Japan. J Geophys Res C Oceans. https://doi. org/10.1029/2020jc016924

Gilbert P, Moore LE (2005) Cationic antiseptics: diversity of action under a common epithet. J Appl Microbiol 99:703-715. https://doi.org/10.1111/j. 1365-2672.2005.02664.x

Gordon HR, Brown OB, Evans RH et al (1988) A semianalytic radiance model of ocean color. J Geophys Res 93:10909. https://doi.org/10.1029/jd093 id09p10909

Huang K, Zhuang Y, Wang Z et al (2021) Bioavailability of organic phosphorus compounds to the harmful dinoflagellate Karenia mikimotoi. Microorganisms. https://doi.org/10.3390/microorganisms9091961

Jiang LL (2014) The backscattering properties of red tide alga and the remote sensing inversion model (Doctoral Thesis). Dalian Maritime University, Dalian

Kurekin AA, Miller PI, Van der Woerd HJ (2014) Satellite discrimination of Karenia mikimotoi and Phaeocystis harmful algal blooms in European coastal waters: Merged classification of ocean colour data. Harmful Algae 31:163-176. https://doi.org/10.1016/j.hal.2013.11.003

Lou X, Hu C (2014) Diurnal changes of a harmful algal bloom in the East China Sea: observations from GOCI. Remote Sens Environ 140:562-572. https:// doi.org/10.1016/j.rse.2013.09.031

Lu D, Goebel J, Qi Y et al (2005) Morphological and genetic study of Prorocentrum donghaiense Lu from the East China Sea, and comparison with some related Prorocentrum species. Harmful Algae 4:493-505. https://doi.org/ 10.1016/j.hal.2004.08.015

Lü S, Cen J, Wang J, Ou L (2019) The research status quo, hazard, and ecological mechanisms of Karenia mikimotoi red tide in coastal waters of China (In Chinese). Oceanol Limnol Sinica 50:487-484

Morel A, Prieur L (1977) Analysis of variations in ocean color1. Limnol Oceanogr 22:709-722. https://doi.org/10.4319/lo.1977.22.4.0709

Robin RS, Kanuri W, Muduli PR et al (2013) Dinoflagellate bloom of Karenia mikimotoi along the southeast Arabian Sea, bordering Western India. $J$ Ecosyst Manage 2013:1-11. https://doi.org/10.1155/2013/463720

Ryu J-H, Han H-J, Cho S et al (2012) Overview of geostationary ocean color imager (GOCl) and $\mathrm{GOCl}$ data processing system (GDPS). Ocean Sci J 47:223-233. https://doi.org/10.1007/s12601-012-0024-4

Shang S, Wu J, Huang B et al (2014) A new approach to discriminate dinoflagellate from diatom blooms from space in the East China Sea. J Geophys Res C: Oceans 119:4653-4668. https://doi.org/10.1002/2014jc009876

Shen YZ, Mao ZH, Tao BY (2013) Scattering properties of two blooming algae: Skeletonema costatum and Prorocentrum donghaiense (In Chinese). J Marine Sci 31(1):45-52

Shen F, Tang R, Sun X, Liu D (2019) Simple methods for satellite identification of algal blooms and species using 10-year time series data from the East China Sea. Remote Sens Environ 235:111484. https://doi.org/10.1016/j. rse.2019.111484

Siswanto E, Ishizaka J, Tripathy SC, Miyamura K (2013) Detection of harmful algal blooms of Karenia mikimotoi using MODIS measurements: a case study of Seto-Inland Sea, Japan. Remote Sens Environ 129:185-196. https://doi.org/10.1016/j.rse.2012.11.003

Tang JL, Mao HY, Guo MR (2006) Analysis on the red tide of Prorocentrum dantatum in the north coastal water of Zhejiang (In Chinese). Marine Enviro Sci 25(3):63-66

Tao B, Mao Z, Lei H et al (2015) A novel method for discriminating Prorocentrum donghaiense from diatom blooms in the East China Sea using
MODIS measurements. Remote Sens Environ 158:267-280. https://doi. org/10.1016/j.rse.2014.11.004

Vaillancourt RD, Brown CW, Guillard RRL, Balch WM (2004) Light backscattering properties of marine phytoplankton: relationships to cell size, chemical composition and taxonomy. J Plankton Res 26:191-212. https://doi.org/ 10.1093/plankt/fbh012

Wang J, Wu J (2009) Occurrence and potential risks of harmful algal blooms in the East China Sea. Sci Total Environ 407:4012-4021. https://doi.org/10. 1016/j.scitotenv.2009.02.040

Xu N, Duan S, Li A et al (2010) Effects of temperature, salinity and irradiance on the growth of the harmful dinoflagellate Prorocentrum donghaiense Lu. Harmful Algae 9:13-17. https://doi.org/10.1016/j.hal.2009.06.002

Yamaguchi H, Kim H-C, Son YB et al (2012) Seasonal and summer interannual variations of SeaWiFS chlorophyll a in the Yellow Sea and East China Sea. Prog Oceanogr 105:22-29. https://doi.org/10.1016/j.pocean.2012.04.004

Zapata M, Fraga S, Rodríguez F, Garrido JL (2012) Pigment-based chloroplast types in dinoflagellates. Mar Ecol Prog Ser 465:33-52. https://doi.org/10. 3354/meps09879

Zhao W, Wang J, Chen M (2009) Three-dimensional fluorescence characteristics of dissolved organic matter produced by Prorocentrum donghaiense Lu. Chin J Oceanol Limnol 27:564-569

Zhou M, Zhu M (2006) Progress of the project "Ecology and oceanography of harmful algal blooms in China" (In Chinese). Chinese J Advan in Earth Sc 21(7):673-679

Zhou M, Yan T, Zhou J (2003) Preliminary analysis of the characteristics of red tide areas in Changjiang River estuary and its adjacent sea. Ying Yong Sheng Tai Xue Bao 14:1031-1038

\section{Publisher's Note}

Springer Nature remains neutral with regard to jurisdictional claims in published maps and institutional affiliations.

\section{Submit your manuscript to a SpringerOpen ${ }^{\circ}$ journal and benefit from:}

- Convenient online submission

- Rigorous peer review

- Open access: articles freely available online

- High visibility within the field

Retaining the copyright to your article

Submit your next manuscript at springeropen.com 